\title{
LOS CLAVES COLONIALES DE SUCRE Y POTOSÍ
}

\author{
Julieta Alvarado
}

\begin{abstract}
By the end of the seventeenth century, the workshops established in the Jesuit missions of South America had already built an array of musical instruments for use in their reductions. Historical documents indicate that the first models of keyboard instruments brought to the region were of Flemish origin. Their original characteristics remain unchanged until the second half of the eighteenth century. Simultaneously, the established route for those destined to the regions of Charcas and Chiquitos, now Bolivia, allows us to track a similarity in instrument building among popular and native instrument workshops. A striking example is clearly noticeable in the two extant eighteenth century harpsichords from the once known as Imperial Village of Potosí and the city of La Plata, present day Sucre. Among the very small number of historical harpsichords preserved in the entire American Continent, these harpsichords differ from other surviving instruments in that they were locally built and therefore exemplify the establishment of a very defined Andean and possibly Amazonic school of harpsichord making. In addition, the panorama presented by the many period organs and other keyboard instruments such as clavichords (many of them still preserved in churches and museums throughout Bolivia), document the legacy of an unprecedented musical flourishing.
\end{abstract}

\section{Resumen}

Hacia fines del siglo XVII los talleres eregidos en las misiones jesuíticas de América del Sur ya fabricaban una gran variedad de instrumentos musicales para su uso en las reducciones. Fuentes historiográficas indican que los primeros modelos de instrumentos de tecla traídos a la region provenían de Flandes. Sus rasgos permanecen casi inmutables hasta la segunda mitad del siglo XVIII. La ruta obligatoria para aquellos destinados a las regiones de Charcas y Chiquitos, hoy Bolivia, nos permite trazar igualmente una semblanza en la trayectoria de construcción establecida entre los talleres populares o nativos. Un ejemplo palpable es apreciable en dos claves dieciochescos procedentes de la otrora Villa Imperial de Potosí y la ciudad de La Plata, hoy Sucre. Entre los poquísimos modelos supervivientes en todo el continente americano, estos claves se diferencian de otros conservados por ser de manufactura local y por consiguiente ponen de manifiesto el establecimiento de una definida escuela andina y posiblemente amazónica de fabricantes de claves. Añadidos a éstos los numerosos órganos y otros instrumentos de tecla como clavicordios - muchos de ellos también conservados en iglesias y museos bolivianos-el panorama documenta el legado de un florecimiento musical sin precedentes.

Este estudio es el resultado de algunas observaciones organológicas dirigidas al análisis de los manuscritos de música de tecla del siglo XVIII presentes en la colección de Concepción, en el Archivo Musical de Chiquitos, Bolivia. Durante el transcurso del estudio de documentos historiográficos relacionados con la construcción de instrumentos musicales, la existencia de dos instrumentos de teclado, casi contemporáneos a los manuscritos de Chiquitos, ha redirigido mi atención a Sucre y a Potosí en estos últimos meses. Los claves coloniales de este estudio, uno perteneciente a la colección de la Fundación Cultural del Banco Central de Bolivia (en el Museo 
Charcas de Sucre), y el otro a la del Convento de Santa Teresa (en el Museo de Santa Teresa en Potosí) son dos modelos representativos de la historia musical de Charcas de mediados del siglo XVIII ${ }^{1}$. Su estudio detallado podrá proporcionar las bases para futuros trabajos de conservación o restauración. A continuación presentaremos algunos antecedentes y resultados de esta investigación.

El clave, como instrumento predilecto en los grandes salones de las cortes europeas hasta casi fines del siglo XVIII, habría sido, sin lugar a dudas, un modelo de instrumento conocido en los nuevos talleres musicales del Nuevo Mundo. Varias crónicas y documentos nos relatan la fabricación de instrumentos musicales desde el Virreinato de Nueva España hasta el Virreinato de La Plata, empezando con la fundación de la primera escuela de música en Texcoco, México, fundada por Fray Pedro de Gante en $1524 .^{2}$ Sabemos también que desde el Altiplano a la Amazonía, en el panorama musical que nos presenta la Audiencia de Charcas, ocurrió un desarrollo musical sin precedentes, fruto de una simbiosis hispano-indígena. En las reducciones jesuíticas entre los guaraníes, chiquitos y moxos, los instrumentos musicales en uso eran casi todos de factura misional. ${ }^{3}$ Hacia fines del siglo XVII en las misiones del Paraguay, los primeros talleres establecidos por el jesuita Anton Sepp ya incluían una variedad de instrumentos, entre ellos claves y órganos. ${ }^{4}$ Es precisamente el Padre Sepp quien, a su llegada de España, trae consigo diversos instrumentos europeos, incluyendo un órgano de los Países Bajos. ${ }^{5}$ Es muy probable que en su colección también se encontrara un clave de la misma región.

Sabemos que instrumentos de los Países Bajos, especialmente claves de procedencia flamenca y particularmente aquellos construídos por miembros de la familia Ruckers, poseían un alto valor, no solo monetario, sino por la alta calidad de su fabricación. El taller de los Ruckers exportaba instrumentos a toda Europa, incluyendo a España. ${ }^{6}$ No sería difícil de imaginarse que Anton Sepp, una figura musical tan importante en las reducciones jesuíticas, educado inicialmente como niño cantor en la catedral de San Esteban en Viena, reconociera la importancia de asegurar para su viaje peregrinatorio a América los mejores modelos de instrumentos musicales a su alcance. Aunque muy pocos son los ejemplos existentes de instrumentos de fabricación flamenca en las Américas, en el Museo de Arte Metropolitano de Nueva York se conserva un virginal muselar doble procedente de los Países Bajos. En su decoración encontramos dos medallones en relieve de Felipe II y su cuarta esposa, Ana de Austria. ${ }^{7}$ Su hallazgo en Oropesa, Perú, muy cerca del Cusco, marca la posibilidad de que haya sido un regalo de este monarca al Virrey

\footnotetext{
1. Museo Colonial Charcas, Sucre, No. de inventario: BC63. Museo de Santa Teresa, Potosí, No. de inventario: Muebles 001.

2. SAldívar, G., Historia de la Música en México, Secretaría de Educación Pública, Editorial "Cultura", México, D.F. 1934, p. 88.

3. HOFFMAN, W., Las Misiones Jesuíticas entre los Chiquitanos, Fecic, Buenos Aires, 1979, p. 147.

4. SEPP, A. - HOFFMAN, W., trad. y ed. crítica, Continuación de las Labores Apostólicas, Editorial. Universitaria, Buenos Aires, 1973, vol. 2, p. 137-139.

5. Ibid.

6. En la Catedral de Segovia existe un clave de un solo teclado, sin fecha, atribuído al taller de los Ruckers, posiblemente Andreas Ruckers (descrito en el Catálogo de la Exposición "Las Edades del Hombre", Catedral de León, 1992).

7. Metropolitan Museum of Art, Nueva York, No. de catálogo: 89.4.2344.
} 
Francisco de Toledo hacia fines del siglo XVI. Beryl Kenyon de Pascual informa que provino de la antigua estancia de los Marqueses de Oropesa, cuyo primer Marqués se casa a fines del siglo XVI con la hija de Atahualpa, último Inca del Perú. ${ }^{8}$ Sin embargo, ha sido fechado ca. 1650 y su roseta, de figura sentada tocando el arpa, lleva las iniciales $C R$. Es atribuído a Christoffel Ruckers. ${ }^{9}$

La primera observación que salta a la vista del organólogo en los claves bolivianos es la similitud de los instrumentos coloniales con los modelos flamencos. De los claves de un solo teclado fabricados por los Ruckers hasta principios de 1700 , el más común parece ser uno que mide $1.830 \mathrm{~mm}$. de largo y $710 \mathrm{~mm}$. de ancho, con una disposición de registros de $1 \times 8^{\prime}$ y $1 \times 4$ ' que accionan el mecanismo del teclado. ${ }^{10}$ La disposición de registros de $1 \times 8^{\prime}$ y $1 \times 4$ ', que accionan el mecanismo de funcionamiento del teclado de los modelos flamencos es idéntica a la de los bolivianos, a excepción de que los flamencos tienen la posibilidad de utilizar sus registros separados o acoplados y los instrumentos de Sucre y Potosí poseen registros fijos.

En las primeras dos vistas podemos ver sendas tomas digitales de los claves de Sucre y Potosí (Ilustración 1). El clave del Museo Charcas, ligeramente mayor en tamaño comparado con el del Museo de Santa Teresa, mide $1.710 \mathrm{~mm}$. de largo y $750 \mathrm{~mm}$. de ancho. El clave de Santa Teresa mide $1.670 \mathrm{~mm}$.de largo y $710 \mathrm{~mm}$. de ancho (Ilustración 2). Estas medidas se aproximan a las proporciones encontradas en los modelos flamencos de un solo teclado.

En las siguientes vistas tenemos los teclados (Ilustración 3). Ambos claves tienen sus teclas blancas recubiertas en hueso pirograbado. Las teclas negras del clave del Museo Charcas tienen interesantes incrustaciones en concha nácar con forma de lágrimas, diamantes y cuadrados sobre nogal. El clave del Museo de Santa Teresa utiliza cedro en las teclas negras. Ambos instrumentos cuentan con arcadas al frente de sus teclas naturales. El teclado abarca cuatro octavas y un total de cuarenta y cinco notas, de Do-1 a do-5, siendo la primera octava inferior la octava corta. Esta amplitud, habitual en los teclados españoles, es típica de los instrumentos de teclado del continente americano, presumiblemente hacia finales del siglo XVIII.

En esta toma (Ilustración 4) podemos apreciar la manufactura del mecanismo del teclado. El diseño es casi igual en ambos, pero la numeración de las teclas muestra manos distintas, lo que sirve de argumento para considerar la posiblidad de un solo taller, pero diferentes fabricantes. Esta hipótesis parece más acertada al examinar los martinetes (Ilustración 5). En estas fotos tenemos evidencia de dos estilos de martinete: el del clave del Museo Charcas en madera sólida, y el clave del Museo de Santa Teresa, con balance o contrapeso de plomo. Esta variación podría indi-

8. KENYON DE PASCUAL, B., "Clavicordios and Clavichords in $16^{\text {th }}$ century Spain", Early Music, Noviembre 1992, p. 618.

9. BOALCH, D. H., Makers of the Harpsichord and Clavichord 1440-1840. Ed. Charles Mould. Clarendon Press, Oxford, 1995, p. 535.

10. Ibid., p. 549-600. También, RUSSELL, R., The Harpsichord and Clavichord, Charles Scribner's Sons, Nueva York, 1973, p. 44. 
car la obra de un maestro y su discípulo. Sin lugar a dudas ambos claves conservan gran cantidad de sus plectros y cuerdas originales y no denotan ningun tipo de restauración.

La roseta adherida a la tabla armónica representa el sello de su constructor. Los instrumentos construidos por los Ruckers se caracterizaban por tener una roseta dorada con una figura sentada tocando el arpa y las iniciales del nombre y apellido del constructor. En el caso de nuestros instrumentos no sólo tenemos una, sino tres rosetas de diferentes tamaños, sin iniciales, estratégicamente colocadas en la tabla armónica (Ilustración 6). Estas tres rosetas no están doradas y presentan algunas diferencias notables (Ilustración 7). A la izquierda, el diseño floral ha sido calado en la misma madera, recordándonos a otro instrumento antiguo, el psalterio. Una roseta casi idéntica a las encontradas aquí, aparece casualmente en un psalterio localizado en la misma sala del clave del Museo de Santa Teresa en Potosí. Sin embargo, el clave de Potosí nos presenta tres rosetas no caladas, sino en pergamino, sobrepuestas en la tabla armónica. Es interesante hacer notar que rosetas en pergamino aparecen con frecuencia en claves italianos y en la entonces conocida como "guitarra española", hoy "guitarra barroca". Rosetas en la entonces Villa Imperial de Potosí pudieron haber sido moldeadas en una base de plata, dada la cercanía del Cerro Rico.

Cerca del teclado encontramos el clavijero (Ilustración 8). Aquí observamos la disposición de los registros de 8' y 4' respectivamente y la similitud de este arreglo en ambos claves. También podemos apreciar la posición de las dos primeras rosetas.

Ahora pasaremos a consideraciones estéticas, fuera de detalles de construcción. Hasta ahora hemos visto grandes similitudes entre dos instrumentos que fácilmente nos llevarían a deducir que su factura es de un mismo taller. Sin embargo, una diferencia notable entre ambos es el hecho de que uno de ellos ha sido decorado totalmente en su exterior, mientras que el otro conserva su madera natural. Interesante desde todo punto de vista es la ausencia del tradicional decorado de la tabla armónica, cuyos dibujos habrían sido plasmados antes de terminar la instalación de las cuerdas, lo que nos lleva a pensar que la decoración que observamos en el exterior del clave del Museo Charcas pudiera haber sido encargada posteriormente a su fecha de construcción. (Ilustración 9a)

En la catalogación del Patrimonio Artístico de la Fundación del Banco Central de Bolivia realizada por José de Mesa y Teresa Aneiva en octubre de 1989, este clave se clasifica como un instrumento en estilo rococó de integridad "incompleta". Vemos que en su estructura de madera de cedro, fueron pintadas flores y otros motivos de la naturaleza, con tonos predominantes en verde y naranja, favoritos en el siglo XVIII. Según observaciones de José de Mesa, el instrumento viene "con tapa policromada que presenta un paisaje con arboleda, fuente y personajes con vestidura asiática"11 (Ilustración 10). La descripción de José de Mesa se refiere a la decoración chinoiserie, un estilo que revoluciona la arquitectura y artes decorativas desde interiores hasta porcelanas. Cerca del año 1305 Marco Polo publica una reseña de sus viajes por Catay, hoy

11. Catalogación de Patrimonio Histórico, Banco Central de Bolivia, Esp. Ins. Música, código BCB-SRE-343, Museo Charcas, No. de inventario BC 63, 1989.

200

(c) Consejo Superior de Investigaciones Científicas Licencia Creative Commons 3.0 España (by-nc)
Anuario Musical, 58 (2003)

http://anuariomusical.revistas.csic.es 
China. Esta publicación eleva la visión fantástica de los europeos hacia el Oriente y desempeña un papel primordial en la creación de chinoiserie, estilo cuya existencia dependía de una asimilación imperfecta y romántica de China. Luego de un lapso de casi trescientos años impuesto por la dinastía Ming, una misión holandesa embarca a Pekín en 1656. Esta misión lleva consigo a Jan Nieuhoff, asistente personal del embajador, hombre observador y artista de profesión. Su libro, que tiene más de cien grabados, fue publicado en 1669 y por primera vez en el Occidente se pudo apreciar una imagen realista de China. ${ }^{12}$ A partir de este momento, diseños derivados de los grabados de Nieuhoff, evolucionan hasta lo que hoy conocemos por chinoiserie. ${ }^{13}$ Existe evidencia de muchos objetos y estilos del Extremo Oriente que presentes entre los gustos de la sociedad americana en los siglos XVII y XVIII. Desconocemos el autor y la fecha en que fue plasmado, pero tenemos seguridad de que, dada la selección de sus colores y la idealización del paisaje y las figuras chinas, fue probablemente inspirada en algún grabado en posesión de sus dueños y ejecutada in situ.

Pedro Querejazu, eminente restaurador boliviano, gentilmente aporta las siguientes observaciones acerca de la decoración del clave del Museo Charcas:

«El tipo de mueble, dado el tipo de patas, se asemeja a las mesas y sillas de factura mediados del siglo XVIII y que se usaron en toda la mitad de ese siglo. Son formas que dejaron de lado las estructuras rectilíneas o torneadas del Renacimiento y del Barroco, para adoptar esta otra forma más grácil que deriva del Rococó, aunque todavía un tanto pesada. En el caso del Neoclasicismo andino hay que considerar que las grandes formas neoclásicas de la arquitectura, apreciables en retablos, como el central y laterales de la Catedral de Sucre, convivieron y aparecieron casi simultáneamente con las formas del Rococó, estilo decorativo de interiores que se manifiesta en el mobiliario. Las patas de este clave, un tanto toscas pero propias del período, corresponden a esas características. (Ilustración 9b)

La policromía exterior del mueble data también de este período. Denota una discreta presencia del estilo neoclásico, que se manifestó en la sustitución del pan de oro por policromado de fondos oscuros de coloración azul-verdosa con decoraciones florales. Sin embargo, no se encuentra todavía la concentración cromática en azul, blanco y rojo bermellón, que caracterizará las últimas décadas del siglo.

La decoración interior, tanto por el tipo de escenas como su coloración y la vestimenta de sus personajes, corresponde a una estética de mediados del siglo XVIII.

Las dos escenas, el grupo musical en torno a un clave, como los personajes en un jardín o huerto arbolado, han tenido que ser tomados de estampas europeas. Por esa época, debido a la influencia de los borbones del entorno de Carlos III, las estampas y los grabados franceses se conocieron bastante, igual que los italianos. El autor de esas pinturas, acaso influído o guiado por el propietario del mueble, pudo usar ese material iconográfico. El artista era ciertamente un personaje no cultivado, un pintor popular. Esto es apreciable en el tipo de pincelada, el manejo del color directo, los colores más bien planos con escasos matices y transiciones, la falta de perspectiva, que un pintor profesional y bien formado habría sabido manejar perfectamente.

12. NIEUHOFF, J. - CHARPENTIER, J. B., trad., "L'Ambassade de la Compagnie Orientale des Provinces Unies vers l'Empereur de la Chine, ou Grand Cam de Tartarie, faite par les Srs. Pierre de Goyer \& Jacob de Keyser”, Jan de Mieurs, Leiden, 1665.

13. Ver: JACOBSON, D., “Chinoiserie”, Phaidon Press Inc., New York, 1999.

Anuario Musical, 58 (2003) 
Sirven de referencia obras profesionales como las pinturas del interior de San Felipe Neri o de Santa Teresa, en La Plata; así como la decoración del órgano de Santa Clara, del último tercio del siglo, cuya decoración fue hecha por una mano profesional que habría que buscar entre Gumiel, Oquendo, Villarroel, y otros neoclásicos activos en La Plata en esos años. La eventual simultaneidad de dos maneras de hacer no debe llamar la atención, es parte de las pervivencias y resistencias que caracterizan al mundo andino desde el barroco hasta el presente.

Un pintor popular, con una estética que todavía puede guardar reminiscencias del barroco, podía perfectamente convivir con un pintor académico llegado desde la metrópoli, tal es el caso de Oquendo, que pocos años después de las fechas de estos instrumentos musicales, trabajaría las ilustraciones cientifistas y neoclásicas para el informe del gobernador Lázaro de Rivera sobre Moxos.» ${ }^{14}$

Una preferencia de decoración tan específica como hemos visto, se realiza normalmente a gusto de su propietario. Por esta razón no es sorprendente que en algunos casos encontremos claves perfectamente terminados como instrumentos musicales y no decorados sobre su madera natural. El clave de Santa Teresa cumple este criterio. Su decoración consiste en el tallado y torneado de su base; su exterior en madera de pino no ha sido modificado, dando resalte a las vetas naturales de la madera, como vemos en su tapa (Ilustración 11).

Si nos fijamos en esta siguiente toma (Ilustración 12) existe un espacio arriba del teclado donde había un pequeño cajón. Su uso es el de guardar herramientas para el clave, tales como la llave de afinar y repuestos, habitual igualmente en los clavicordios. Este instrumento fue presentado como dote de una novicia carmelita al Convento de Santa Teresa en Potosí. Generalmente la segunda hija de una familia española de la alta sociedad potosina recibiría este honor. En caso de tener que completar la dote, la familia ofrecería sus más preciadas posesiones para asegurar el ingreso de su hija al convento. Este clave, por consiguiente, fue una muy preciada posesión familiar. Sabemos que el talento musical de una nueva novicia era siempre favorecido en los conventos y en muchos casos, ayudaba a reducir la suma de la dote. El detalle del cajón, aunque ya desaparecido, es una evidencia más del mismo taller de construcción, ya que esta peculiaridad aparece en el mismo lugar arriba del teclado del clave del Museo Charcas, pero en este caso el cajón está con su instrumento (Ilustración 13).

Ya hemos visto el uso de concha nácar en el teclado de este instrumento. Material de importación, sabemos que los artesanos la trabajaban localmente. He aquí la última evidencia irrefutable de que se trata de una factura local: la incorporación de fauna nativa en los diseños del cajón (Ilustración 14). Hemos podido detectar varias figuras de animales que algún día nos contarán la verdadera historia de su presencia en este instrumento. Entre las visibles tenemos, a la izquierda, un armadillo; al centro, un felino; a la derecha, una vizcacha (su forma en nácar ha desaparecido). Arriba del felino vemos una forma de sagrado corazón. A la derecha, al final, un pez. Todos estos animales aparecen en la región andina y la pregunta que nos formulamos es: ¿cuál es la relación entre estas figuras y el dueño o la dueña del clave, para ocupar un lugar tan

14. Correspondencia con Pedro Querejazu, 30 de octubre y lo. de noviembre, 2002. 
prominente en la decoración del instrumento, justo arriba del teclado? La respuesta quizás podamos encontrarla dentro del cajón (Ilustración 15).

“De mi Sra. Dña. Petita Lemoine, Año de 17...”

¿Quién era la Sra. Dña. Petita Lemoine?

Investigando los antecedentes del apellido Lemoine en Sucre, descubrí que el primer Lemoine en emigrar a la ciudad de La Plata en el año de 1752 fue Jean-Baptiste, más tarde conocido como Juan Bautista Lemoine, natural de los Reinos de Francia. ${ }^{15}$ Casado en 1766 con Bárbara Villavicencio, natural de La Plata, continúa como residente de esta ciudad y tiene seis hijos, entre ellos Petrona, nacida en junio de $1770 .{ }^{16}$ El 8 de diciembre de 1786, a los dieciséis años de edad, es casada con Ramón García Pérez, natural de la ciudad de La Coruña, en el Reino de Galicia. ${ }^{17}$ Es Don Ramón García Pérez el firmante en este pequeño cajón, y su joven esposa Petrona ("Petita") la dueña del clave. ${ }^{18}$

El éxito de esta identificación resuelve sólo en parte, los interrogantes alrededor de este clave. Como podemos notar, el año está cubierto por una mancha muy oscura. Gracias al excelente equipo del Archivo y Biblioteca Nacionales de Bolivia (ABNB) hemos podido descifrar recientemente esta incógnita para su divulgación. La escritura en cuestión se realiza en el primer año de matrimonio de Petita: 1787. Es poco probable que esta indicación de año nos indique la fecha de construcción del clave. Sin embargo, siendo Petita aún muy joven, su instrumento pudo haber sido regalo de su padre, un francés al servicio del ejército español en La Plata, familiarizado con la popularidad del estilo chinoiserie en su tierra natal.

Pensamos también que los animales tienen alguna afinidad con su dueña. ¿Quizás parte de alguna historia o cuento? ¿Mascotas favoritas? Lo que sí parece reafirmarse, en base a los detalles de construcción ya mencionados es que, tanto este clave como el clave de Santa Teresa parecen ser construídos localmente en Potosí o en La Plata (Sucre) y por consiguiente deben ser considerados como claves bolivianos. ¿Qué mejor modelo podríamos tener para ejecutar el rescatado repertorio boliviano de música de tecla del Archivo Musical de Chiquitos? La conexión no es imposible, ya que en Moxos se ofrece a las ciudades de Charcas claves y otros instrumentos por encargo. ${ }^{19}$ El Archivo y Biblioteca Nacionales de Bolivia también cuenta con un Método de Clave y Armonía escrito por el catalán Benito Bails. ${ }^{20}$ Fechado 1775 , fácilmente hubiera podido servir como base de aprendizaje a Doña Petita.

15. Existe, curiosamente, otro contemporáneo de nombre Jean-Baptiste Lemoine, nacido en Eymet, Francia en 1751. Este último es un compositor francés educado con Kirnberger en Berlín. En 1786 estrena en París su exitosa ópera Phèdre y viaja a Italia en 1787. Muere en París en 1796. Véase The Harvard Biographical Dictionary of Music, Don Michael Randel, editor (Cambridge: Harvard University Press, 1996), p. 496.

16. ABAS, AP, Sagrario de Guadalupe, Matrimonios (1748-1775), Sucre.

17. ABAS, AP, Sagrario de Guadalupe, Matrimonios (1780-1800), Sucre.

18. Podría tratarse de una españolización del francés "petite", por ser hija menor, o un diminutivo de Petrona, caso de escasa frecuencia en los libros santorales de Charcas de este período.

19. ABNB, Mojos y Chiquitos (Mojos 1787) . MyCh 209 s.n., 20f., Sucre.

20. ABNB, Sucre. 
Durante el transcurso de la investigación nos hemos topado con otros datos que, a su vez, pueden ayudar a contestar otras preguntas ajenas a este tema. Petita Lemoine, como hemos mencionado, es la segunda hija del matrimonio de Juan Bautista Lemoine y Bárbara Villavicencio. Le antecede Michaela, y le siguen Juan Manuel, María Bárbara Francisca, José Mariano y José Joaquín (Ilustración 17). En un retrato, depositado en la Casa de la Libertad en Sucre, vemos a José Joaquín de Lemoine, hermano menor de Petita Lemoine y héroe de la Independencia de América. Junto a su hermano Juan Manuel, en la noche del 25 de mayo de 1809 ganaron la torre de San Francisco e hicieron sonar las campanas que convocarían al pueblo contra el Presidente de la Audiencia, en la primera gesta libertaria hacia la Independencia de Bolivia. ${ }^{21}$ (Ilustración 16)

A modo de conclusión, la siguiente tabla comparativa resume los puntos principales de esta investigación en espera de posteriores estudios de estos dos claves coloniales, únicos en las Américas y aún inmutables al paso de los siglos

21. Ver notas del Catálogo de Exposición Histórica Itinerante que acompaña el retrato al óleo de José Joaquín de Lemoine en: Primera Gesta Libertaria, Ind. Gráficas Qori Llama, Sucre, 2000. 


\begin{tabular}{|c|c|c|}
\hline CLAVES & $\begin{array}{l}\text { MUSEO COLONIAL } \\
\text { CHARCAS, SUCRE }\end{array}$ & $\begin{array}{l}\text { MUSEO DE SANTA } \\
\text { TERESA, POTOSI }\end{array}$ \\
\hline Tipo & clave de un solo teclado & clave de un solo teclado \\
\hline Fecha & $\sin$ fecha & $\sin$ fecha \\
\hline Inscripciones & $\begin{array}{l}\text { De mi Sra. Dña. Petita Lemoine } \\
\text { Año de 17(87) } \\
\text { (escritura dentro de un cajón } \\
\text { ubicada directamente arriba del } \\
\text { teclado) }\end{array}$ & ninguna \\
\hline Disposición & $1 \times 8^{\prime}, 1 \times 4^{\prime}$, registros fijos & $1 \times 8^{\prime}, 1 \times 4^{\prime}$, registros fijos \\
\hline Extensión & Dol-do5, octava corta & Do1-do5, octava corta \\
\hline Estilo del teclado & $\begin{array}{l}\text { teclas blancas recubiertas en hueso } \\
\text { pirograbado, teclas negras en } \\
\text { nogal con incrustaciones en } \\
\text { concha nácar }\end{array}$ & $\begin{array}{l}\text { teclas blancas recubiertas en hueso } \\
\text { pirograbado, teclas negras en } \\
\text { cedro }\end{array}$ \\
\hline Rosetas & 3 & 3 \\
\hline Estilo de rosetas & madera calada & pergamino \\
\hline Caja exterior & $\begin{array}{l}\text { cedro policromado, al estilo } \\
\text { chinoiserie }\end{array}$ & pino, base en madera de cedro \\
\hline Construcción de la caja & estilo flamenco & estilo flamenco \\
\hline Escala & $\mathrm{do} 4=340 \mathrm{~mm}$ & $\mathrm{do} 4=360 \mathrm{~mm}$ \\
\hline Largo & $1.720 \mathrm{~mm}$ & $1.670 \mathrm{~mm}$. \\
\hline Ancho & $750 \mathrm{~mm}$ & $710 \mathrm{~mm}$ \\
\hline Altura de la caja & $230 \mathrm{~mm}$. & $200 \mathrm{~mm}$ \\
\hline Espesor de las paredes & $8 \mathrm{~mm}$ & $8 \mathrm{~mm}$ \\
\hline Espesor de la tapa inferior & $8 \mathrm{~mm}$ & $10 \mathrm{~mm}$. \\
\hline Espesor de la tabla armónica & $4 \mathrm{~mm}$. & $5 \mathrm{~mm}$. \\
\hline No. de inventario & $\mathrm{BC} 63$ & Muebles 001 \\
\hline Procedencia & $\begin{array}{l}\text { Museo Colonial Urioste Arana, } \\
\text { Sucre }\end{array}$ & Convento de Santa Teresa, Potosí \\
\hline
\end{tabular}




\section{Ilustración 1}

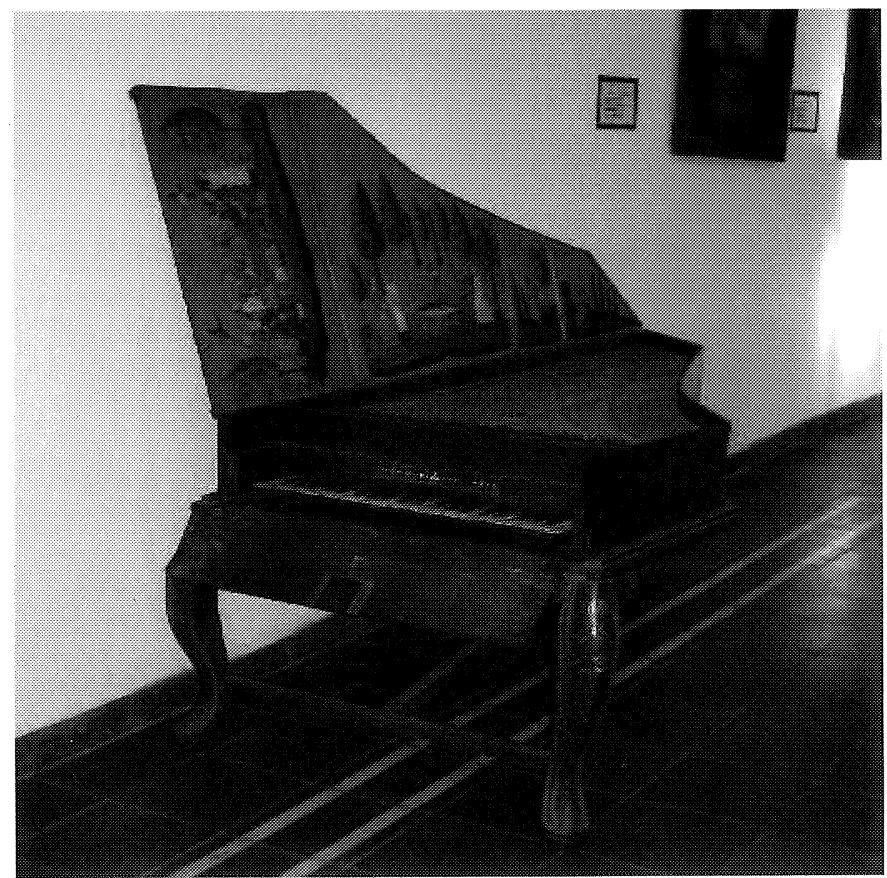

Clave del Museo Charcas (vista frontal)

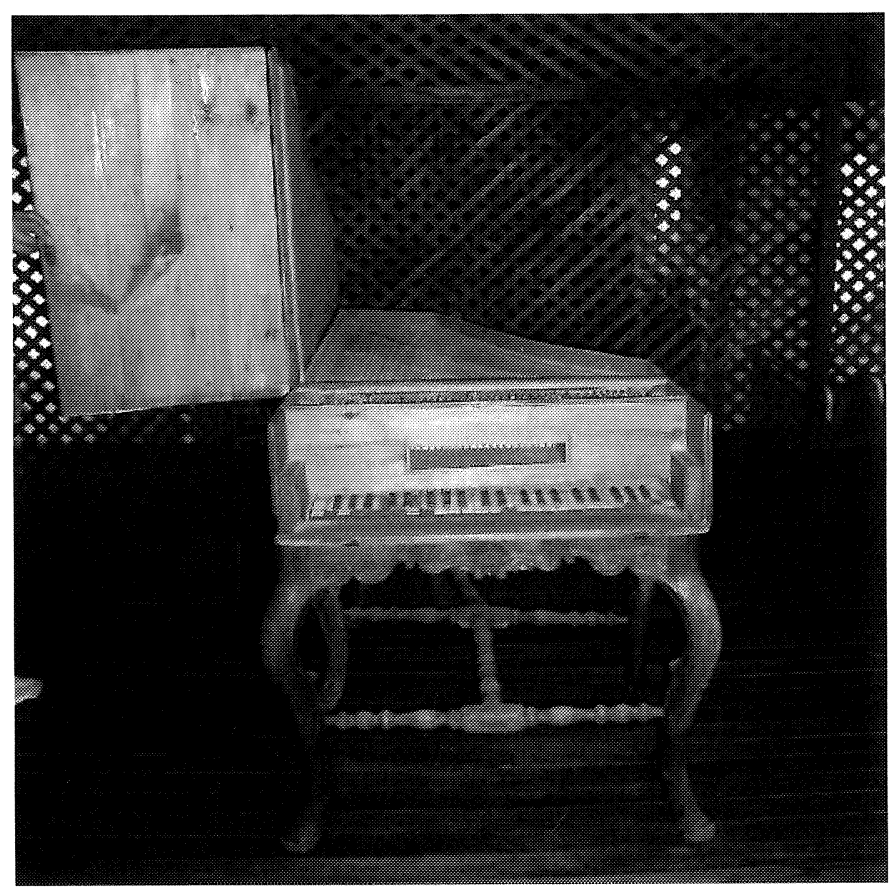

Clave del Museo de Santa Teresa (vista frontal) 


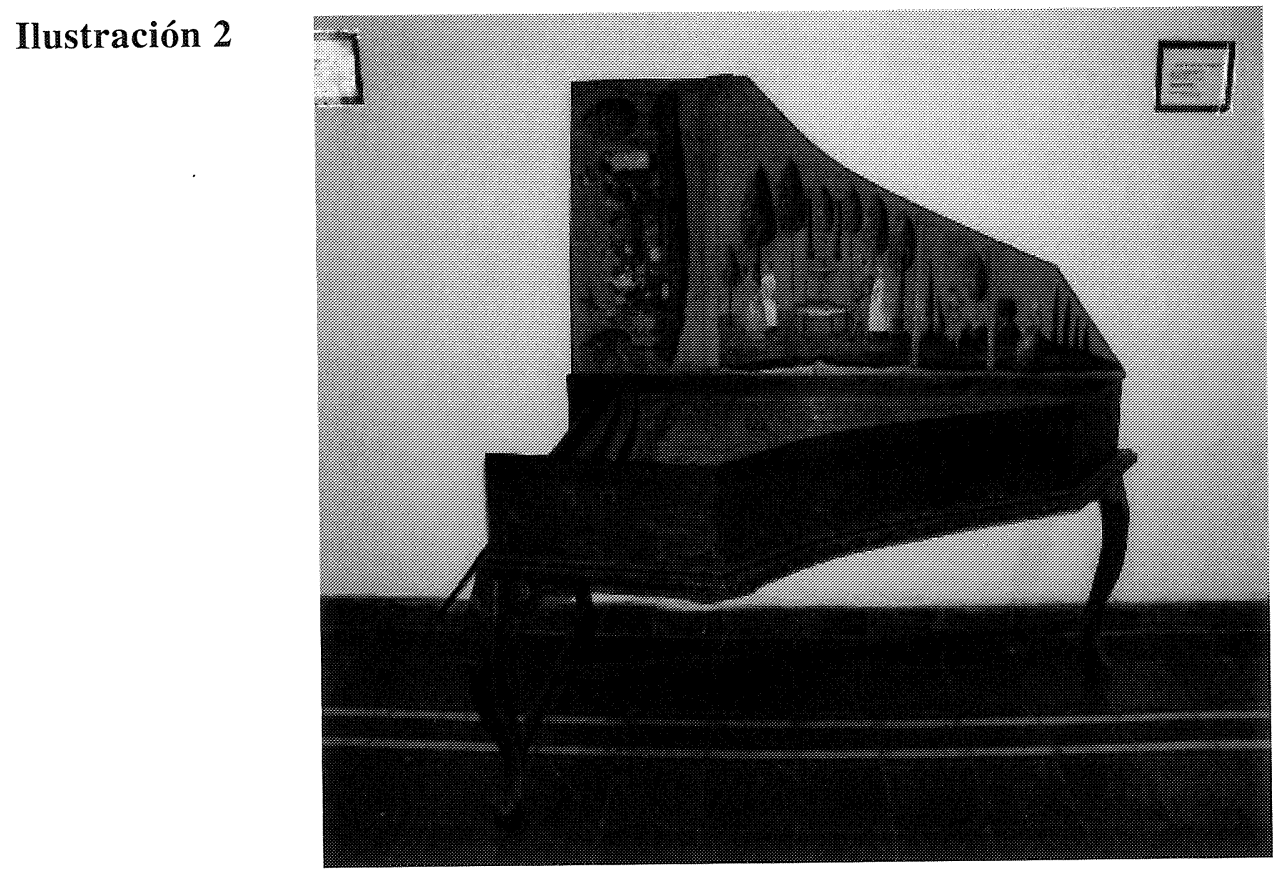

Clave del Museo Charcas (vista lateral)

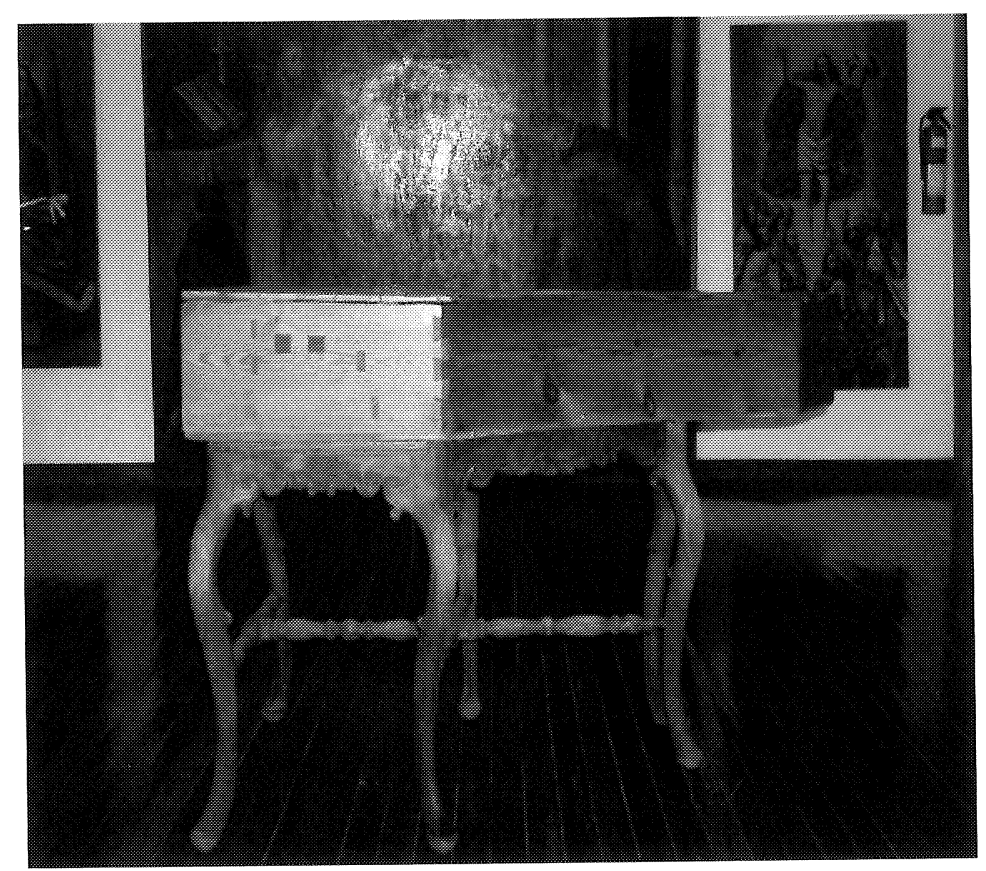

Clave del Museo de Santa Teresa (vista lateral) 


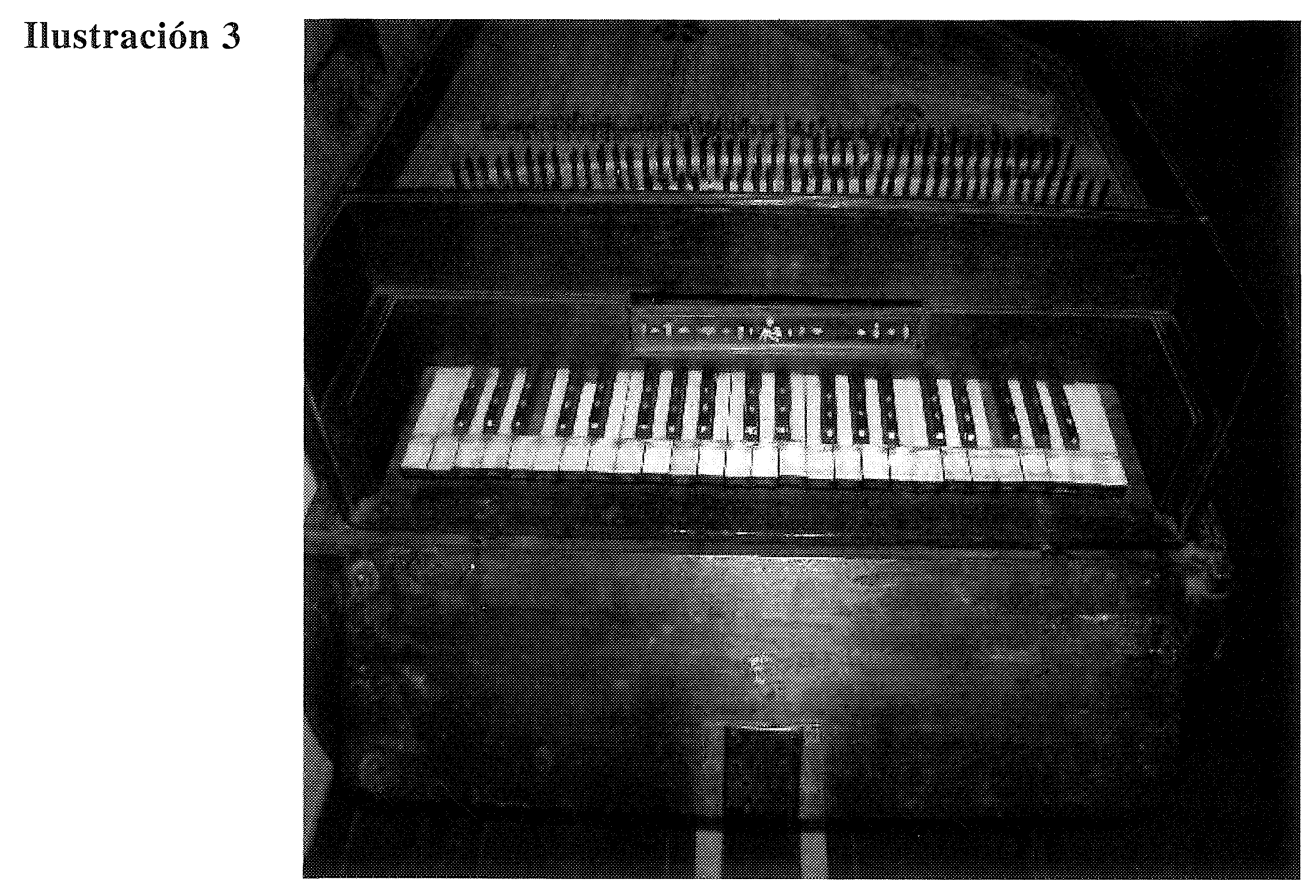

Clave del Museo Charcas (teclado)

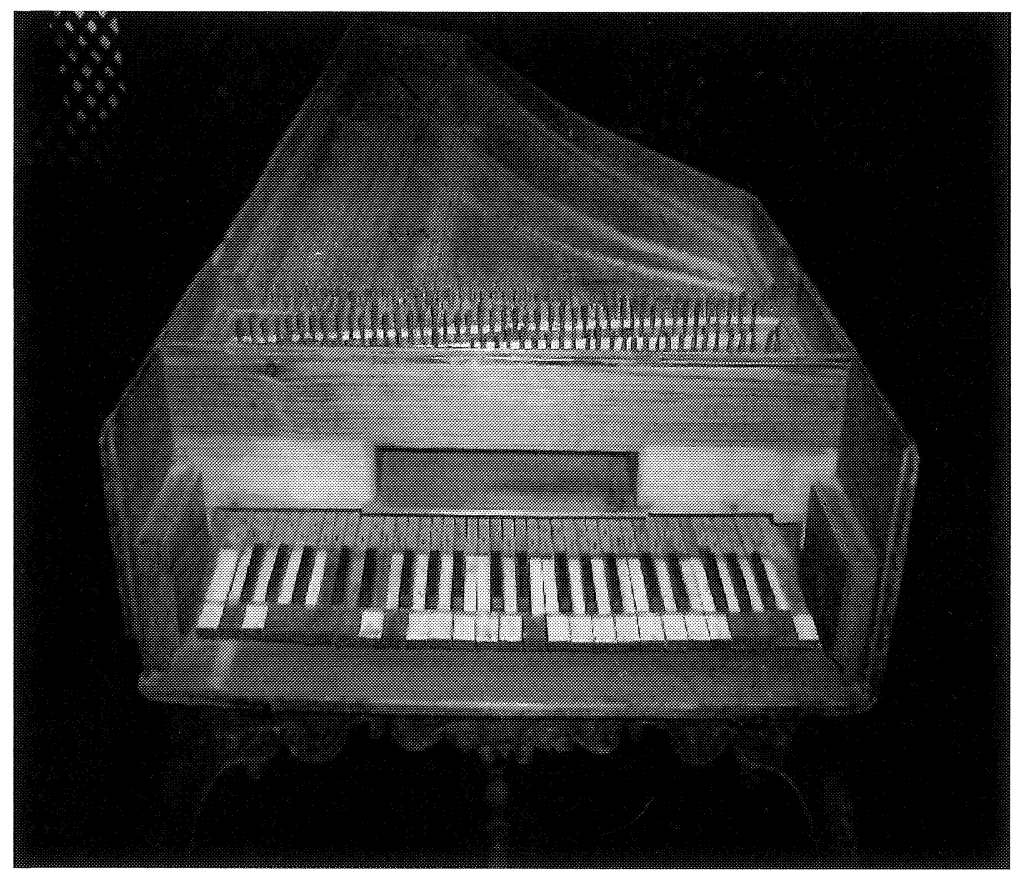

Clave del Museo de Santa Teresa (teclado) 


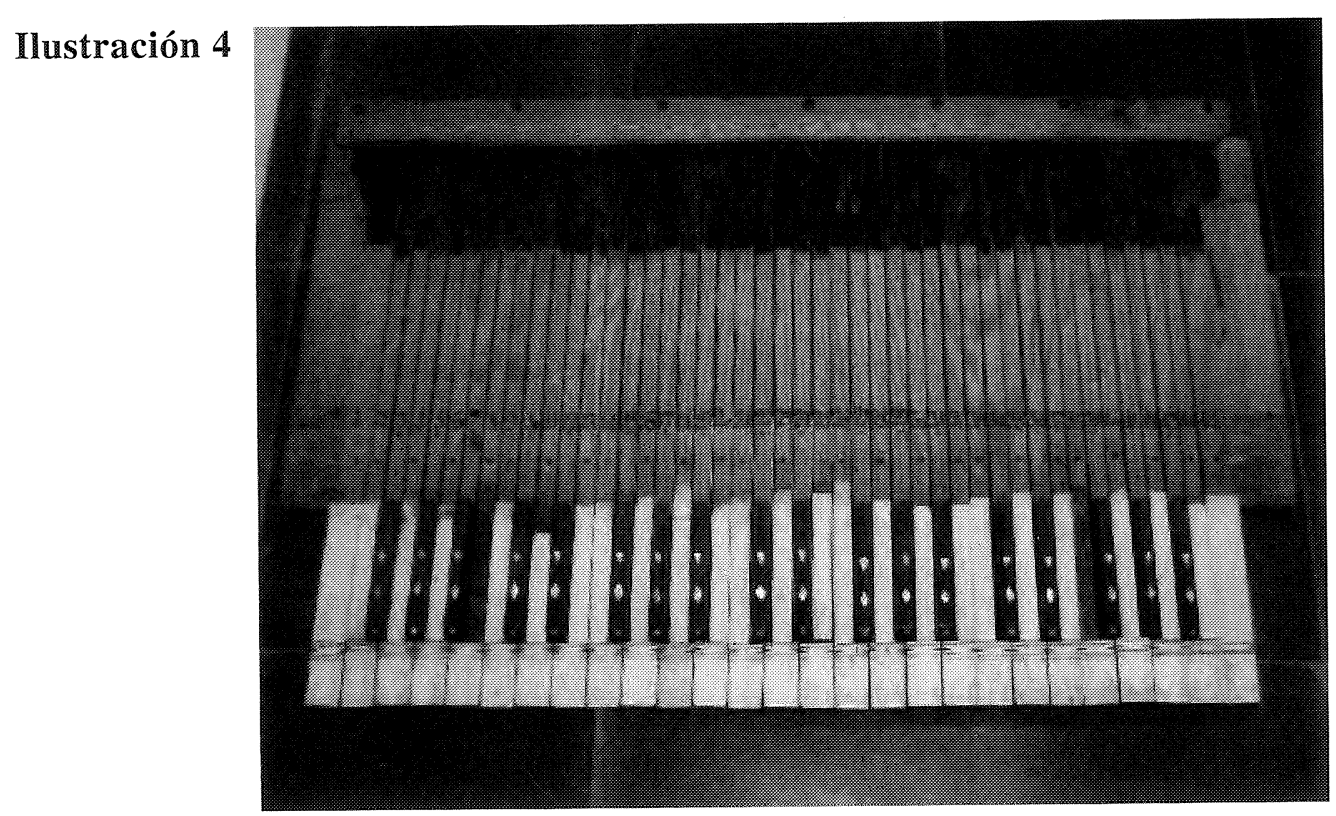

Clave del Museo Charcas (mecanismo)

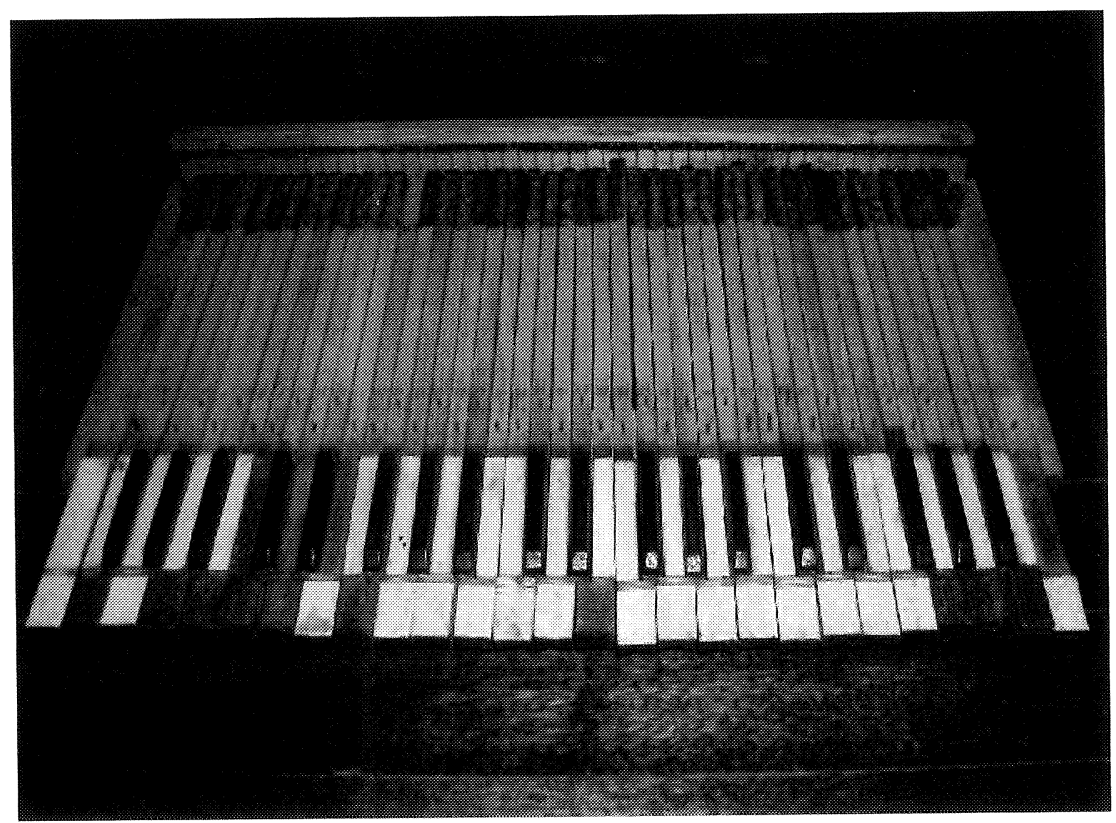

Clave del Museo de Santa Teresa (mecanismo) 


\section{Ilustración 5}

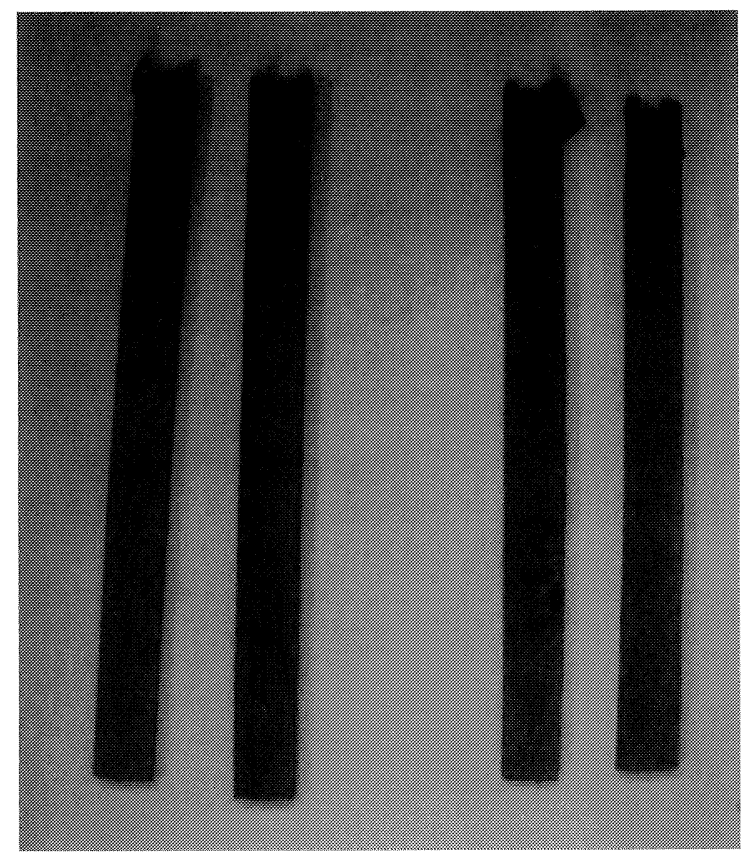

Clave del Museo Charcas

(martinetes - detalle)

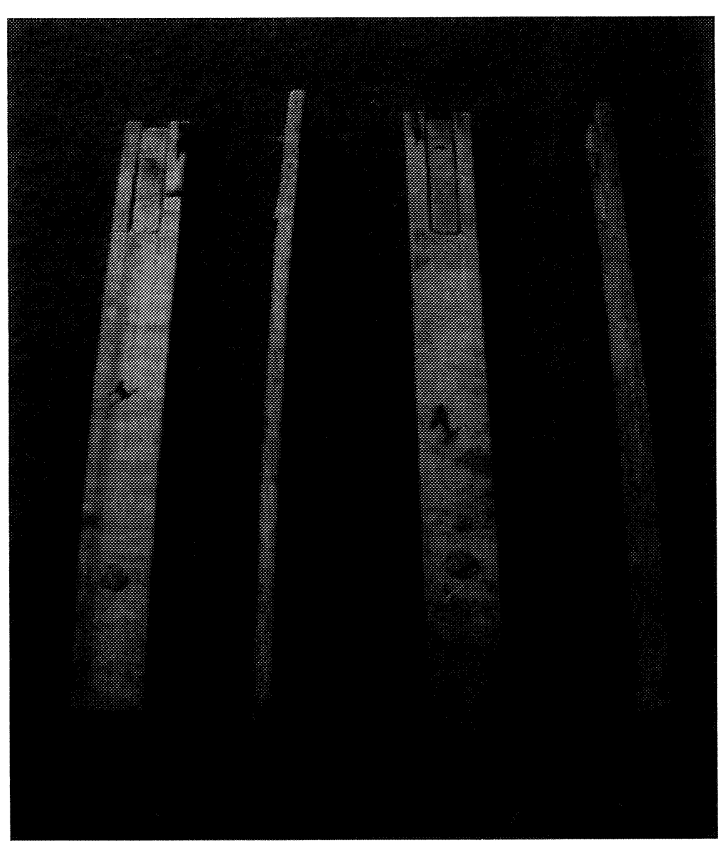

Clave del Museo de Santa Teresa

(martinetes - detalle) 


\section{Ilustración 6}

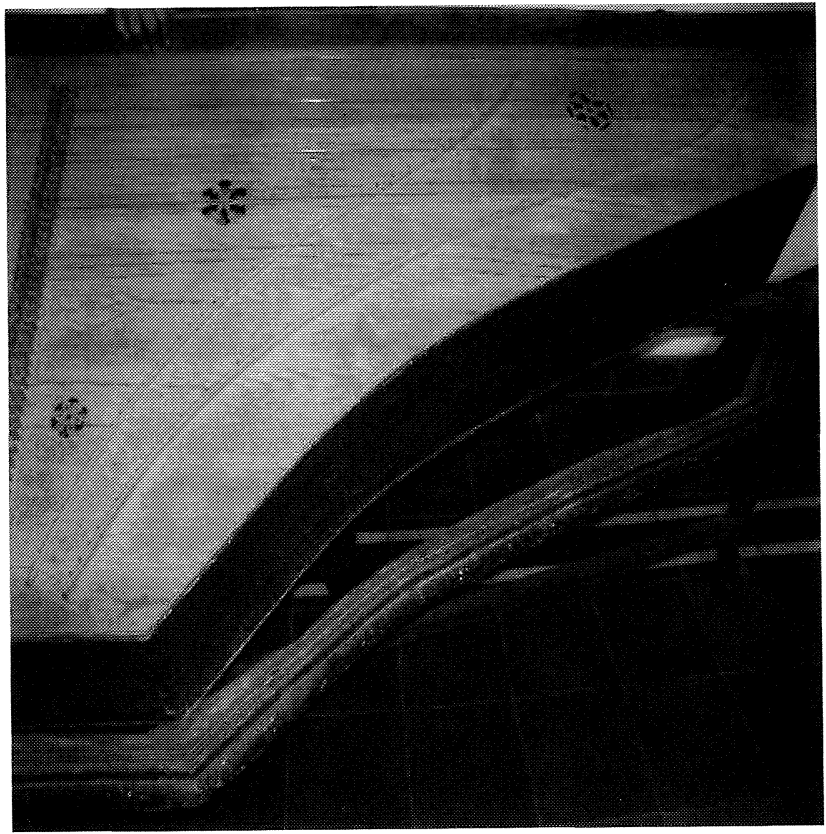

Clave del Museo Charcas (rosetas)

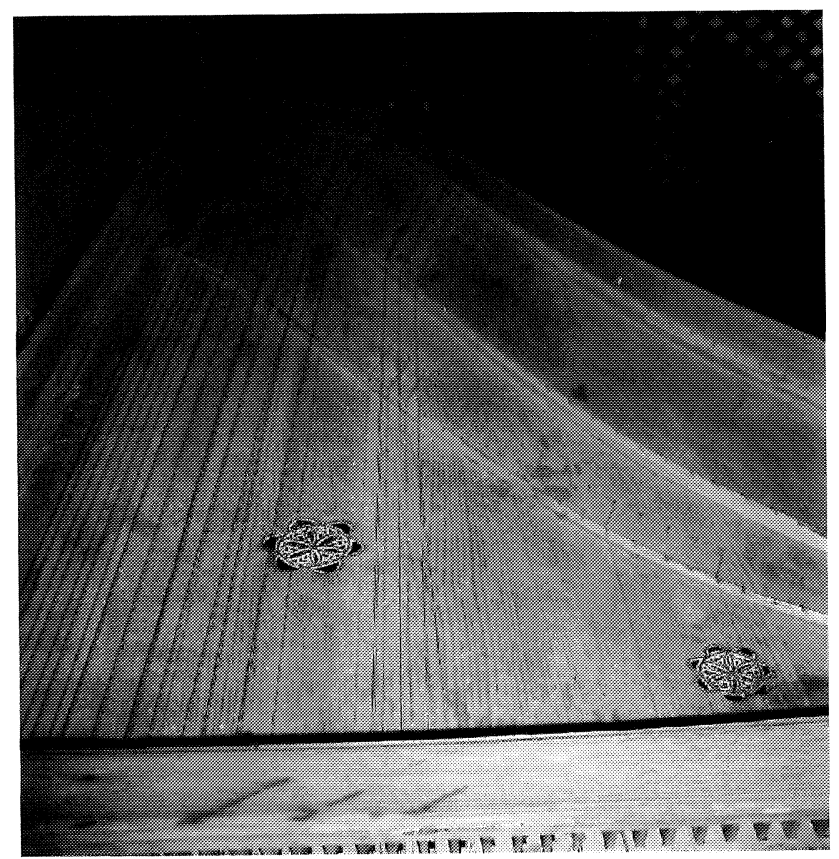

Clave del Museo de Santa Teresa (rosetas) 


\section{Ilustración 7}

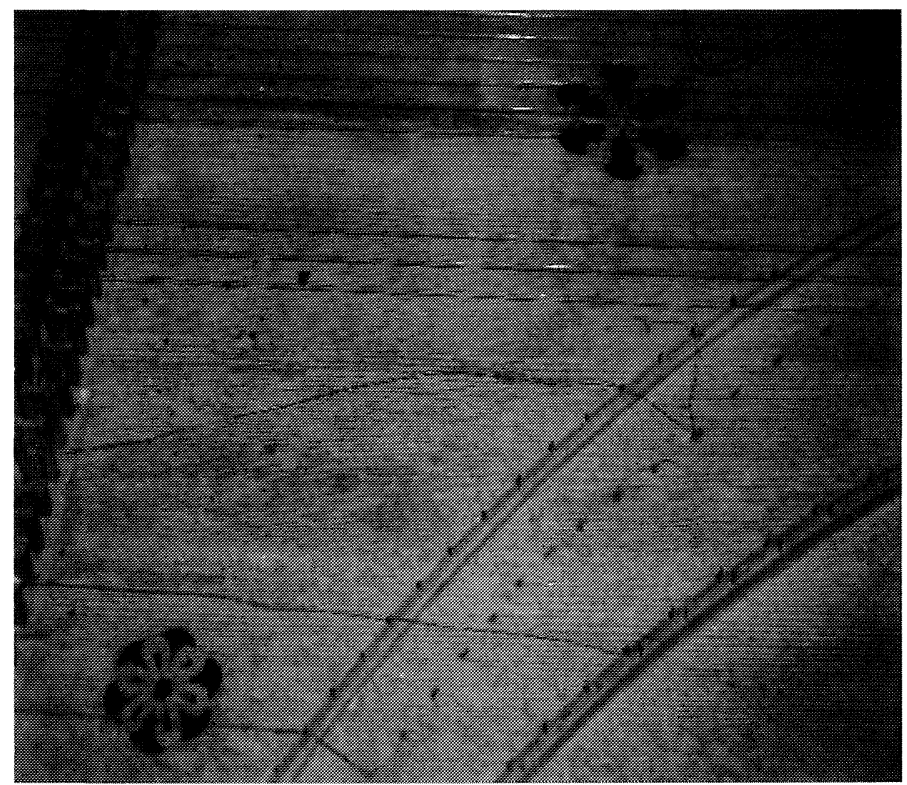

Clave del Museo Charcas (rosetas - detalle)

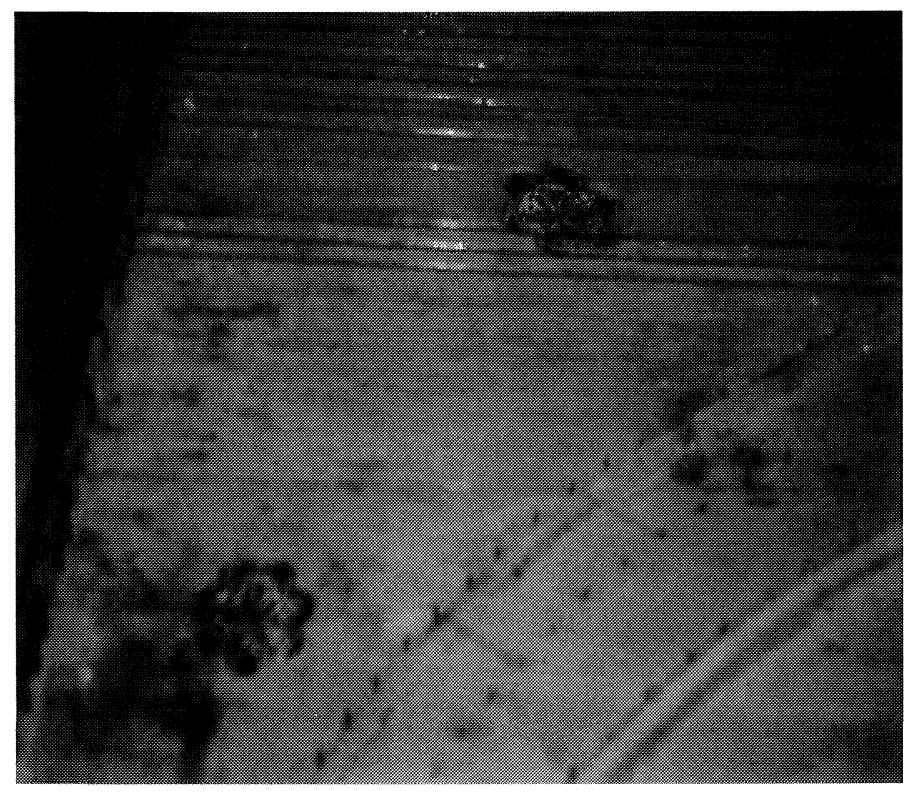

Clave del Museo de Santa Teresa (rosetas - detalle) 


\section{Ilustración 8}

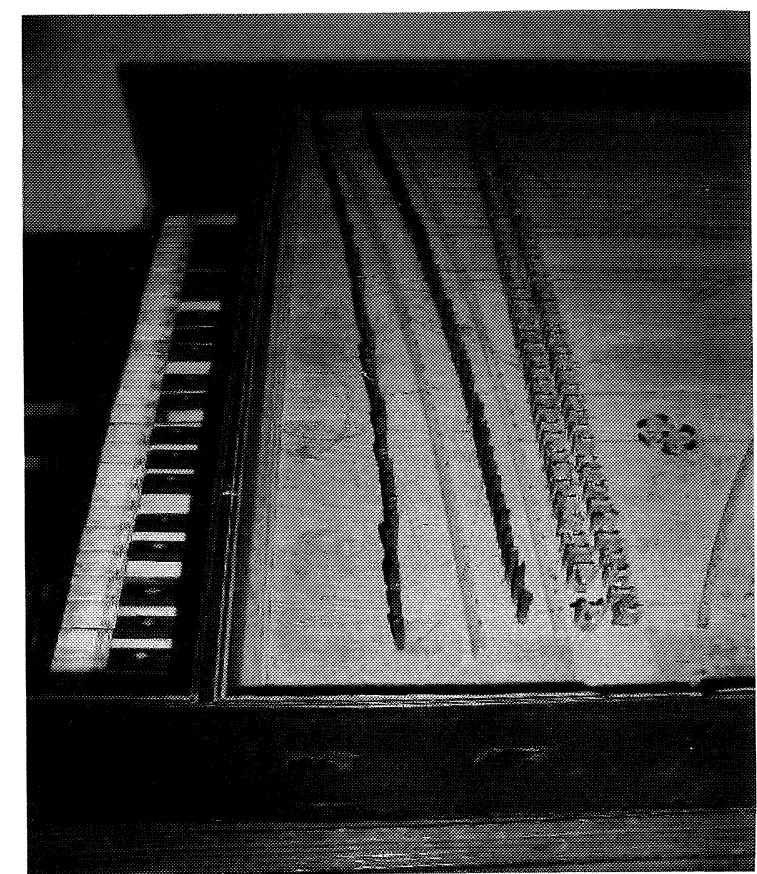

Clave del Museo Charcas (clavijero)

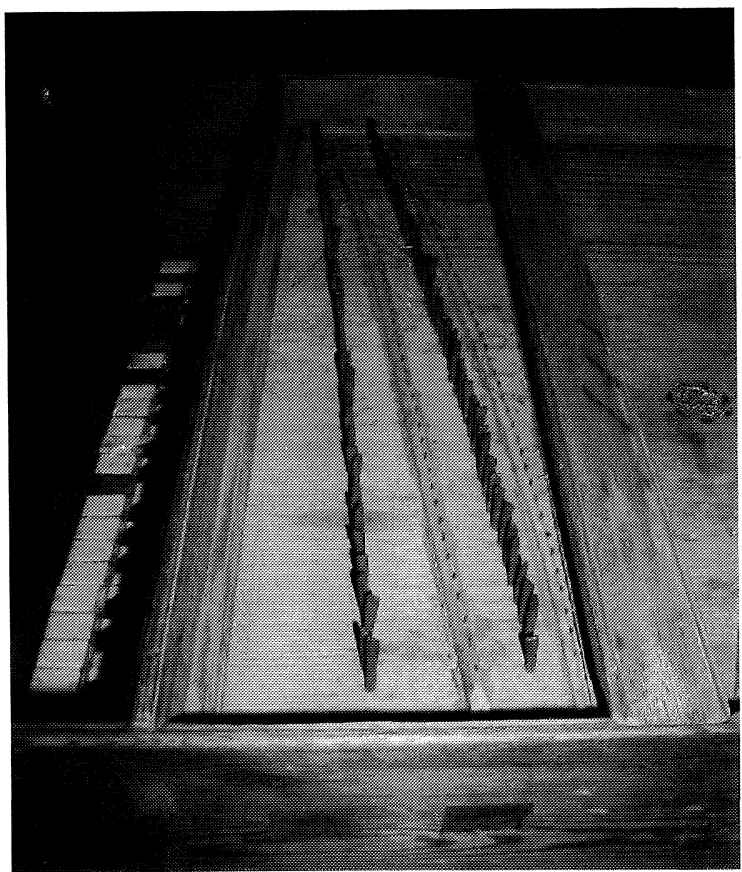

Clave del Museo de Santa Teresa (clavijero) 


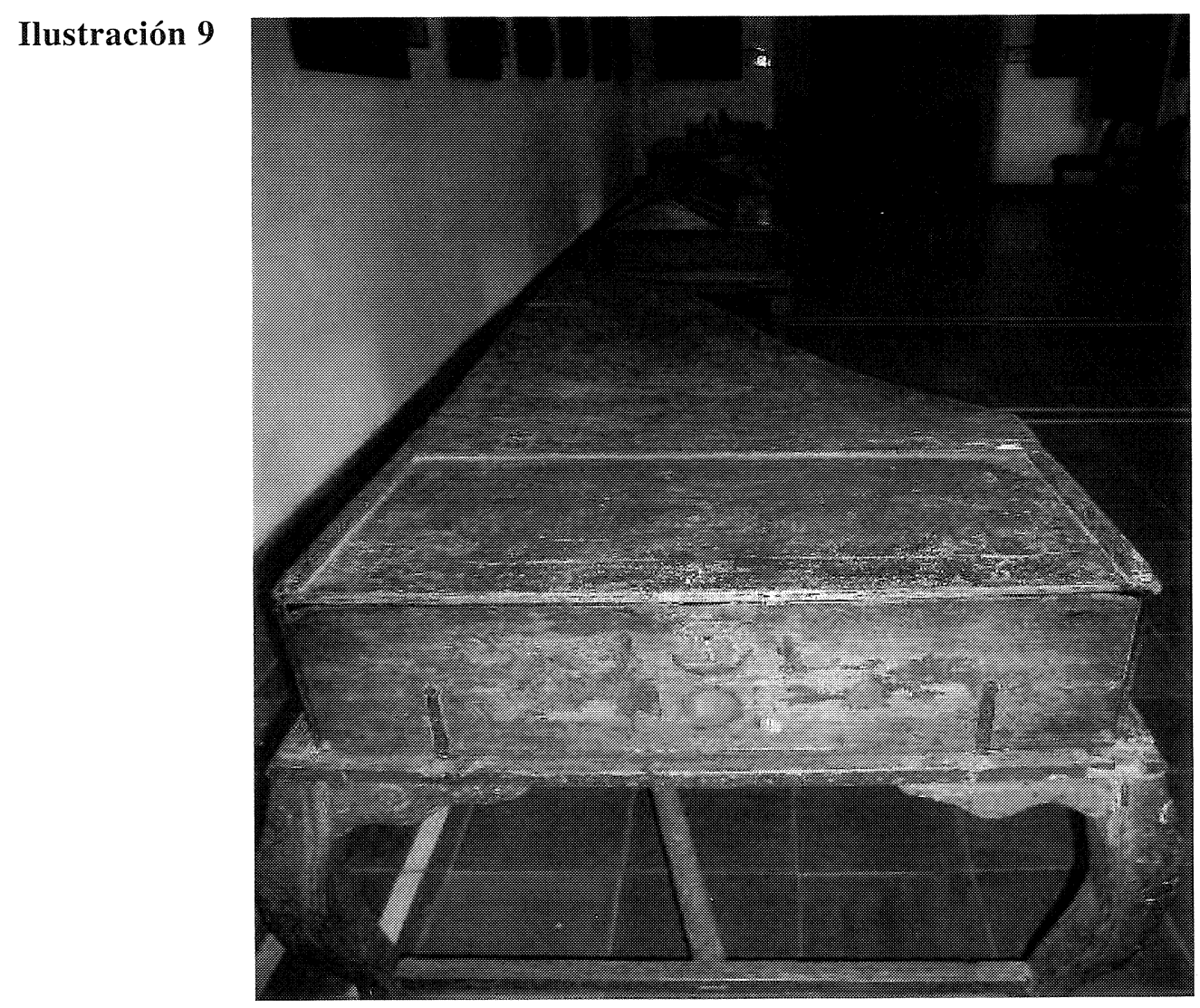

a) Clave del Museo Charcas (decorado exterior)

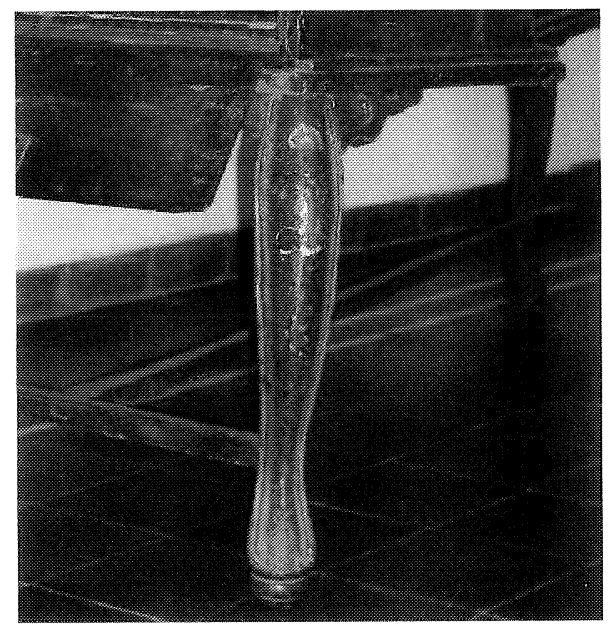

b) Clave del Museo Charcas (decorado - detalle) 


\section{Ilustración 10}

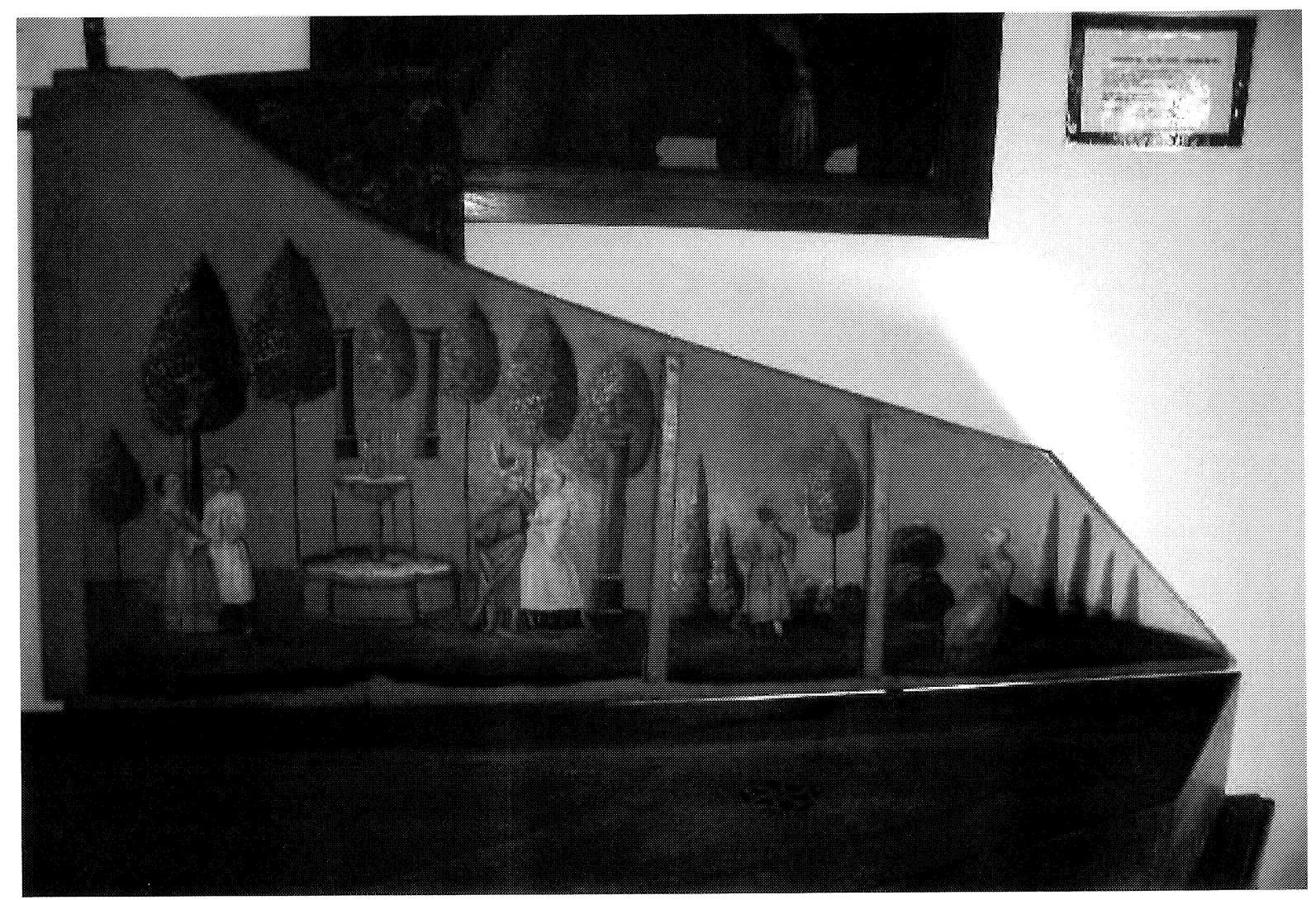

Clave del Museo Charcas (tapa interior - estilo chinoiserie) 


\section{Ilustración 11}

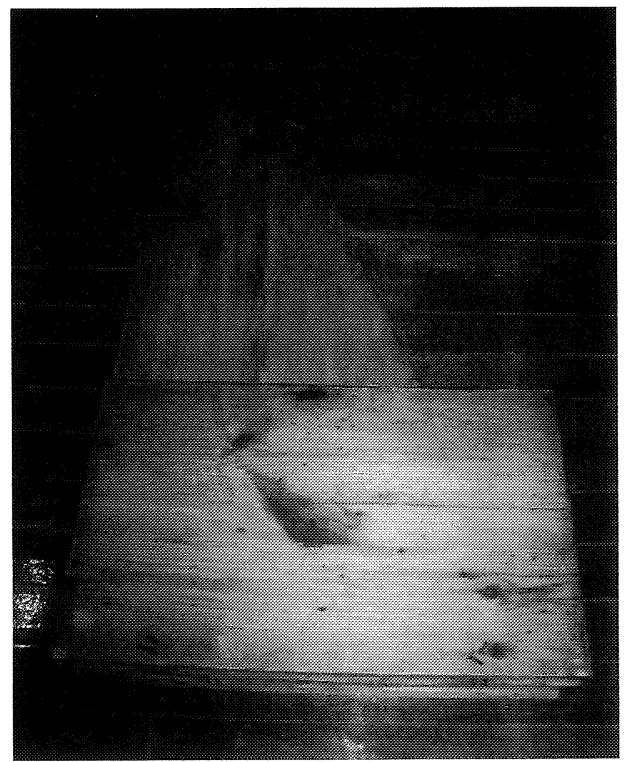

Clave del Museo de Santa Teresa

(Tapa - madera natural de pino)

\section{Ilustración 12}

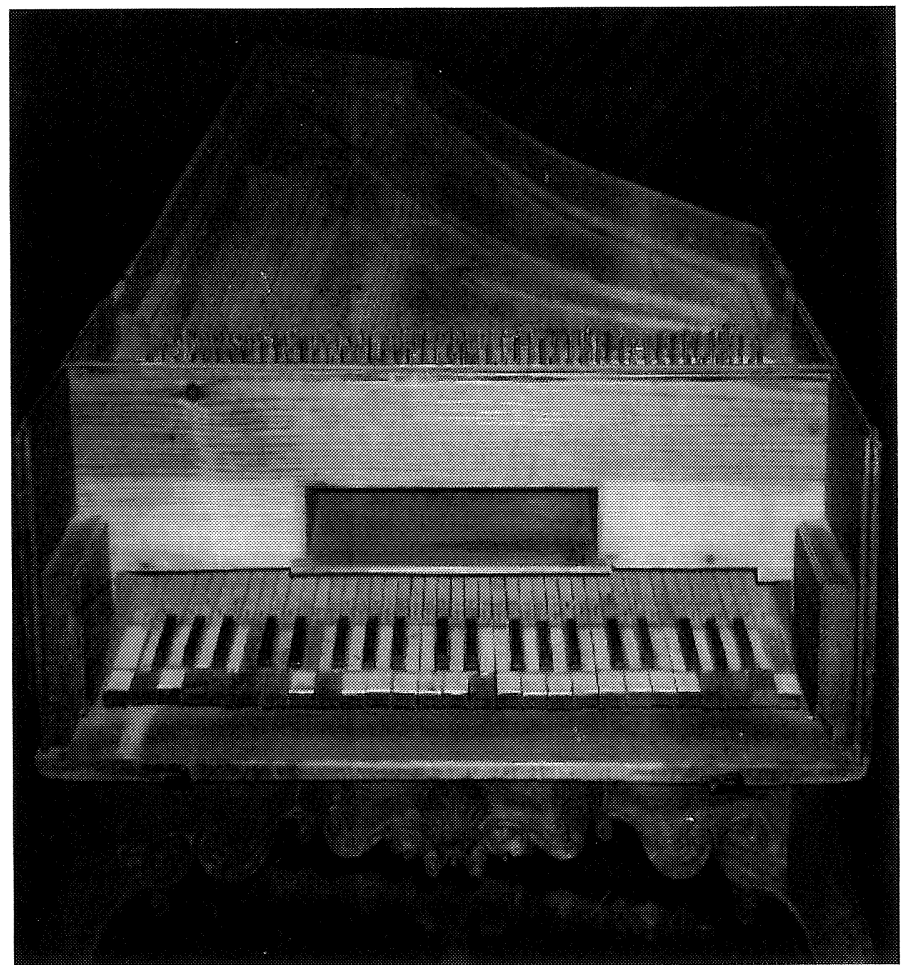

Clave del Museo de Santa Teresa (caja - detalle) 
Ilustración 13

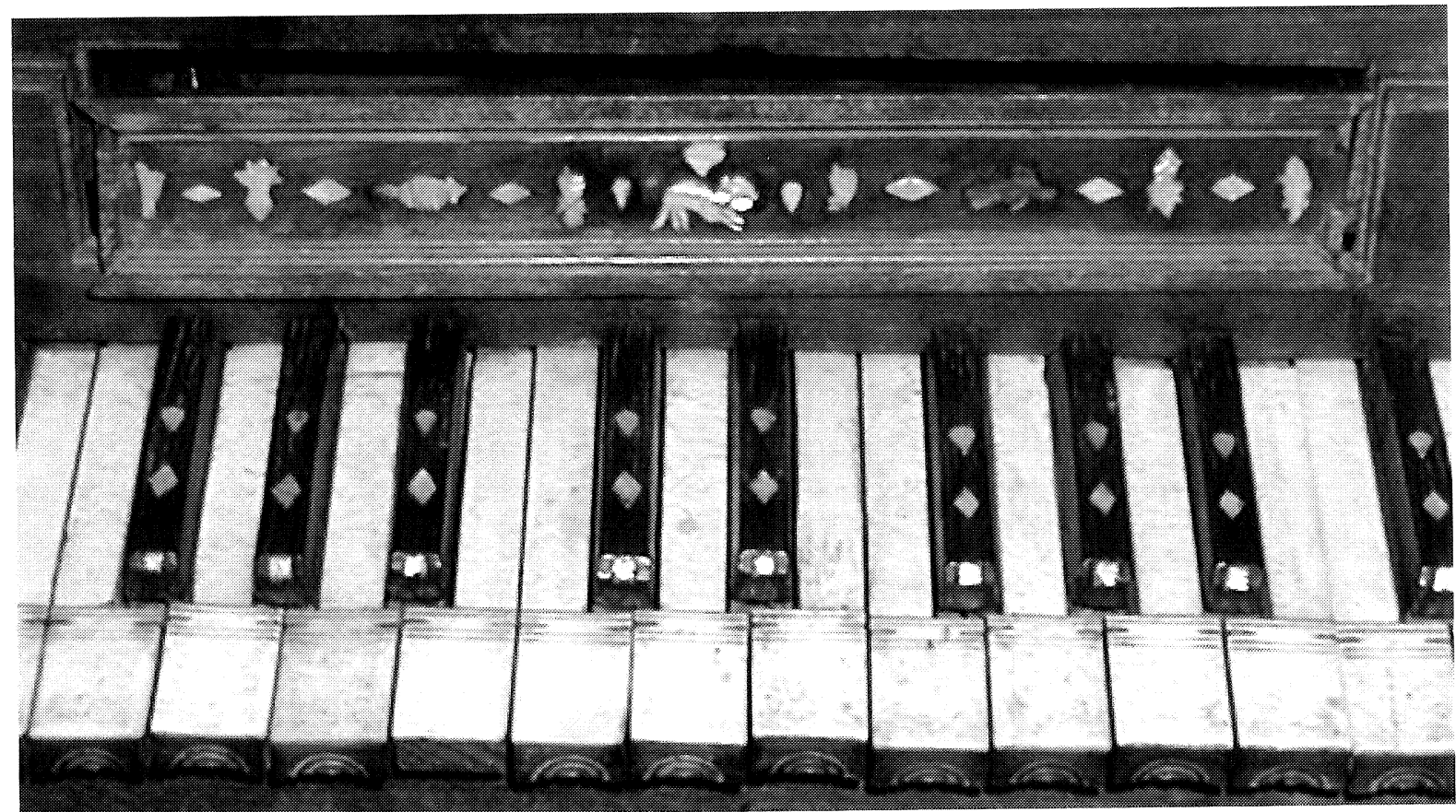

Clave del Museo Charcas (cajón - detalle 1)

\section{Ilustración 14}

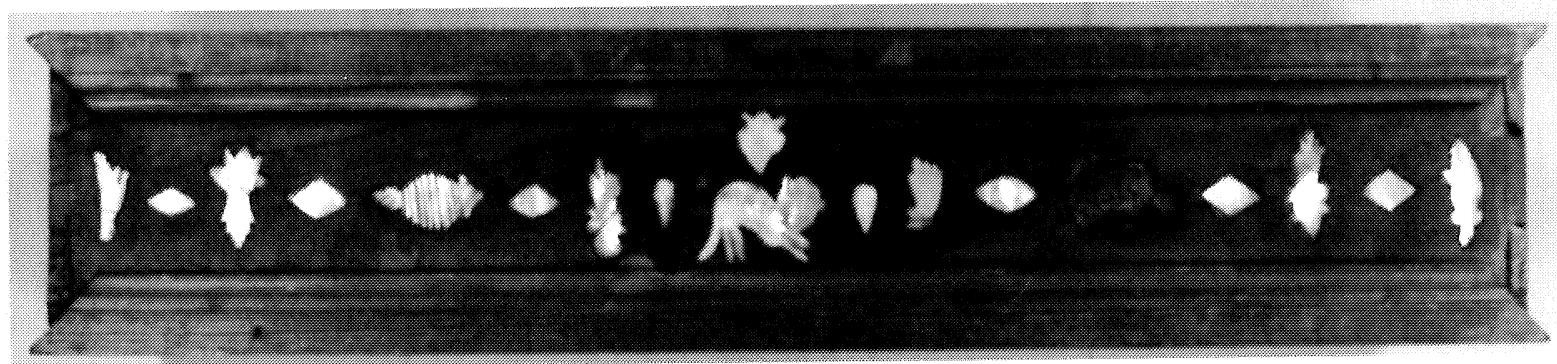

Clave del Museo Charcas (cajón - detalle 2) 


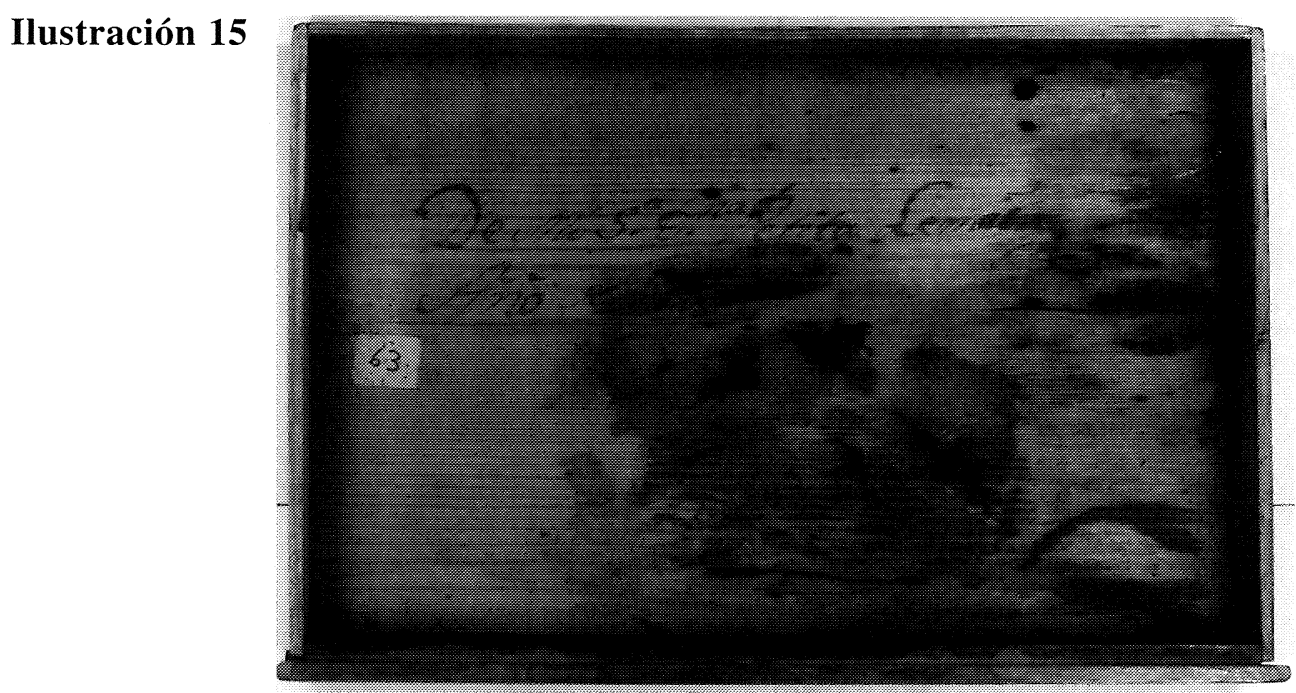

Clave del Museo Charcas (cajón - firma interior)

\section{Ilustración 16}

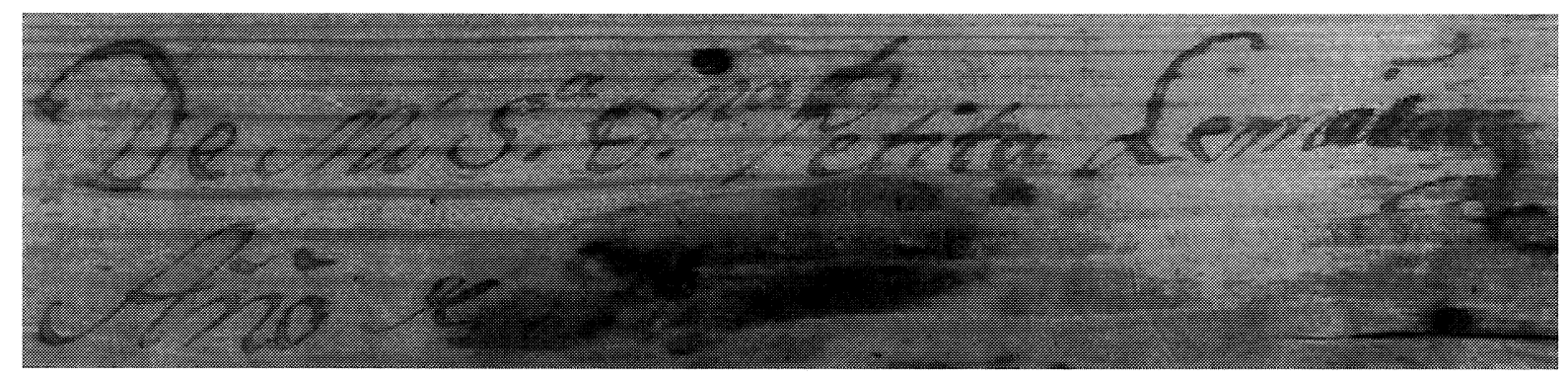

Clave del Museo Charcas (cajón - detalle)

\section{Ilustración 17}

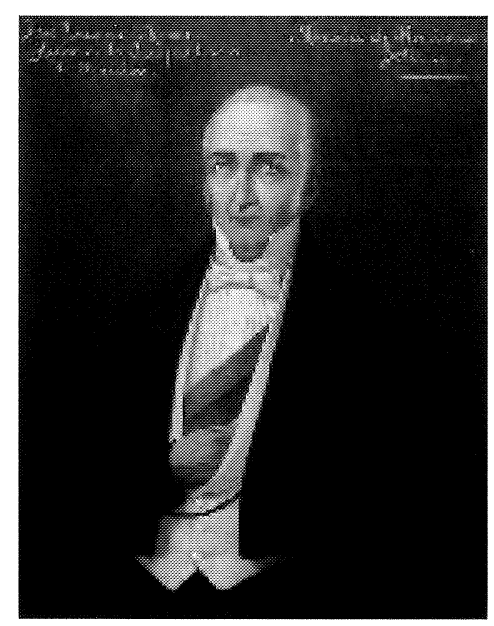

José Joaquín Lemoine 